Ege Tıp Dergisi / Ege Journal of Medicine 2019;58(1):55-58

\title{
Kronik tip a aort diseksiyonunun cerrahi tedavisinde erken dönem sonuçlar
} The early outcomes of surgical therapy for chronic type a aortic dissection

\author{
Serkan Ertugay ${ }^{1}$ Anıl Apaydın ${ }^{1}$ Bora Baysal ${ }^{2}$ B \\ ${ }^{1}$ Ege Üniversitesi Tıp Fakültesi, Kalp ve Damar Cerrahisi Anabilim Dalı, İzmir, Türkiye \\ ${ }^{2}$ Biruni Üniversitesi Tıp Fakültesi Kalp ve Damar Cerrahisi Anabilim Dalı, İstanbul Türkiye
}

\section{Öz}

Amaç: Akut tip A aort diseksiyonlarının yaklaşık \%10'u, semptomların olmaması veya tanı konulamamasına bağlı olarak kronikleşmektedir. Bu hastalarda klinik gidiş, cerrahi strateji ve sonuçlar farklılıklar göstermektedir. Bu çalışmada amaç kronik tip A aort diseksiyonu nedeniyle opere edilen hastaların erken dönem sonuçlarını analiz etmektir.

Gereç ve Yöntem: Çalışmaya 2001-2014 yılları arasında, kronik tip A aort diseksiyonu nedeniyle ameliyat edilen toplam 41 hastanın verileri retrospektif olarak analiz edildi. Bu hastaların 28' i erkek (\%68) ve yaş ortalaması $55,9 \pm 13$ yıl idi. Hastaların öyküsünde en sık saptanan risk faktörleri hipertansiyon (\%65), koroner arter hastalığı (\%22) idi. Tüm hastaların 13 tanesinde $(\% 31,7)$ geçirilmiş aort veya diğer kardiyak cerrahi öyküsü mevcuttu. Cerrahi insizyon olarak hastaların çoğunda (\%95) median sternotomi uygulandı.

Bulgular: Cerrahi teknik olarak 20 hastaya basit tüp greft replasmanı, 15 hastada aort kökü kondüit greft replasmanı, 6 hastada total arkus replasmanı uygulandı. Beyin koruma stratejisi olarak derin hipotermik sirkülatuar arrest $(\% 82,9)$, ve antegrad serebral perfüzyon $(\% 17,1)$ uygulandı. Tüm hastalarda saptanan ortalama kardiyopulmoner by-pass süresi $210,1 \pm 67 \mathrm{dk}$, miyokard iskemi süresi ise $116,3 \pm 43 \mathrm{dk}$ olarak saptandı. Ortalama serebral iskemi süresi $27,6 \pm 9$ dakika olarak bulundu. Postoperatif 3 hastada reeksplorasyon gerektiren kanama, 5 hastada uzamış mekanik ventilatör desteği gerekmiştir. Hastaların ortalama yoğun bakım kalış süresi $4,1 \pm 5$ gün

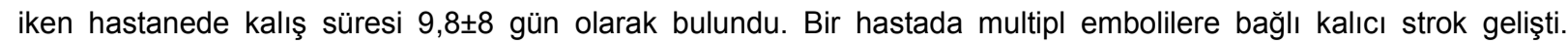
Mortalite bir hastada (\%2) görülmüş olup bu hastada ölüm nedeni embolik strok olarak kaydedilmiştir.

Sonuç: Kronik tip A aort diseksiyonlu hastaların cerrahi tedavisinde düşük mortalite oranı uygun strateji ile sağlanabilir. Strok en önemli mortalite nedeni olarak göze çarpmaktadır.

Anahtar Sözcükler: Kronik aort diseksiyonu, aort replasmanı, strok, mortalite.

\section{Abstract}

Aim: Approximately $10 \%$ of acute type A aortic dissections become chronic due to lack of symptoms or nondiagnosis. Clinical course, surgical strategy and outcomes differ. This study aims to analyze early outcomes of surgical treatment for chronic type A aortic dissection.

Materials and Methods: Forty-one patients operated for chronic type A aortic dissection between 2001 and 2014 , were included in this study and the data were analyzed retrospectively. Mean age $55.9 \pm 13$ years and $68 \%$ were male. The common risk factors for aortic dissection were hypertension (65\%) and coronary artery disease (22\%). Thirteen patients (31\%) were previously operated for aortic or other cardiac procedure. Surgical incision was median sternotomy in most of patients (95\%).

Results: The common procedures were tube graft replacement (20 patients), valved-conduit graft replacement for aortic root (15 patients) and total arch replacement (6 patients). Deep hypothermic circulatory arrest was used in 34 patients and additional antegrad cerebral perfusion in 7 patients, as brain protection strategy. The mean duration of cardiopulmonary bypass, myocardial ischemia time and cerebral ischemia were $210.1 \pm 67,116.3 \pm 43$ and $27.6 \pm 9$ min, respectively. The common complications were re-exploration for bleeding in 3 patients, need for prolonged

\footnotetext{
Yazışma Adresi: Serkan Ertugay

Ege Üniversitesi Tıp Fakültesi, Kalp ve Damar Cerrahisi

Anabilim Dalı, İzmir, Türkiye

E-posta: serkanertugay80@gmail.com

Makalenin Geliş Tarihi: 25.03.2018 Kabul Tarihi: 04.04.2018
} 
ventilator support in 5 patients. Mean intensive care unit and hospital stay was found $4.1 \pm 5$ days and $9.8 \pm 8$ days, respectively. Permanent stroke was observed in one patient because of multiple embolisms. Mortality was observed in one patient (\%2) due to embolic stroke.

Conclusion: A low mortality rate can be achieved with appropriate strategy in the surgical treatment of chronic type A aortic dissection. Stroke seems to be the common cause of mortality.

Keywords: Chronic aortic dissection, aortic replacement, stroke, mortality.

\section{Giriş}

Akut tip A aort diseksiyonu (AAAD), hayatı tehdit eden ciddi bir aort hastalığıdır. Bu hastaların \%40'ı akut safhada hastaneye ulaşamadan kaybedilirken, hastaneye ulaşan hastalarda saatlik mortalite riski \%1, operatif mortalite riski ise \%10-25 arasındadır $(1,2)$. Rüptür, ciddi aort yetmezliği ve malperfüzyon nedeniyle mutlaka acil cerrahi onarım gereklidir.

Akut safhada semptom olmaması, hastanın normotansif olması ve küçük merkezlere başvurma gibi nedenlerden dolayı tanı konulamayan hastalarda aort patolojisi kronikleşebilir (3). Ancak akut safhadan kronik safhaya geçme oranı sadece \%10'dur (4). Bunun yanında kronik tip $A$ aort diseksiyonu (KAAD) gelişen olguların üçte birinde geçirilmiş kardiyak cerrahi öyküsü saptanmaktadır (4). Aort diseksiyonu geliştiği ilk 14 günden sonra mortalite riski düşmekte, bu günden sonra kronik diseksiyon olarak tanımlanmaktadır (5). KAAD gelişen hastalarda başvuru şekli, aort patolojisi ve cerrahi sonuçlar farklııklar gösterir (2). Bu hastalarda cerrahi tedavi gerekliliği hastanın semptomlarına, asendan aortanın çapına ve aort yetmezliğinin ciddiyetine bağlıdır.

Bu çalışmadaki amaç, kliniğimizde kronik tip A aort diseksiyonu nedeniyle ameliyat edilen hastaların erken dönem sonuçlarının analiz edilmesidir.

\section{Gereç ve Yöntem}

Çalışmaya 2001-2014 yılları arasında, kronik tip A aort diseksiyonu nedeniyle ameliyat edilen toplam 41 hasta dâhil edilmiştir. Hasta verileri retrospektif olarak, dosya tarama metodu ve aort cerrahisi veri bankasından elde edildi. Bu hastaların 28 ' i erkek (\%68) ve yaş ortalaması $55,9 \pm 13$ yıl idi. Hastaların başvurularında en sık semptomlar göğüs ağrısı ve nefes darlığı olarak saptandı. Hastaların öyküsünde en sık saptanan risk faktörleri hipertansiyon (\%65), koroner arter hastalığı (\%22) idi. Tüm hastaların 13 tanesinde $(\% 31,7)$ geçirilmiş aort veya diğer kardiyak cerrahi öyküsü mevcuttu.

Cerrahi insizyon olarak hastaların çoğunda median sternotomi, sadece 2 hastada bilateral anterior torakotomi (Clamshel) uygulandı. Kardiyopulmoner by-pass için seçilecek arter kanülasyon yerine detaylı bilgisayarlı tomografi değerlendirmeleri neticesinde karar verildi ve sıklıkla femoral arter ile sağ subklaviyan artere yerleştirildi (Şekil-1).

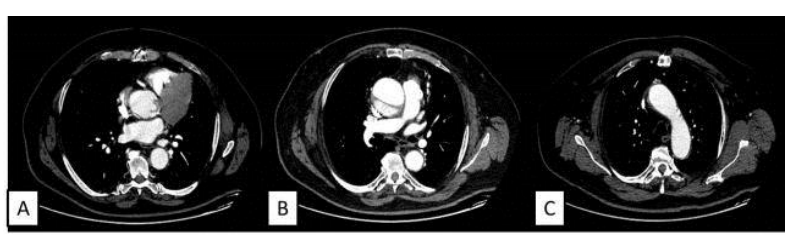

Şekil-1. Kardiyak cerrahi sonrası gelişen kronik tip A aort diseksiyonunun gösteren 3 kesitte bilgisayarlı tomografi görüntüleri. A. Aort kökü seviyesi. B. Pulmoner arter bifurkasyon seviyesi. Bu kesitte aortanın en geniş çapı 60 $\mathrm{mm}$. C. Asendan aorta distali, diseksiyon flebi kaybolmaktadır.

Miyokard koruması için hastaların hepsinde antegrad kardiyoplejiye ek olarak retrograd kan kardiyoplejisi kullanıldı. Derin hipotermik sirkülatuar arrest uygulanan hastalarda vücut ISISI $15-18^{\circ} \mathrm{C}$ arasına kadar düşürüldü. Isınma ve soğuma sırasında alfa stat ile asit-baz dengesi sağlandı. Preoperatif ve bazı operatif özelikler Tablo-1'de verilmiştir.

Tablo-1. Preoperatif Hasta Özellikleri.

\begin{tabular}{l|c|c}
\hline Özellik & Sayı & Yüzde (\%) \\
\hline Yaş & $55,9 \pm 13$ yıl & \\
\hline Cinsiyet & & \\
$\quad$ Erkek & 28 hasta & 68 \\
$\quad$ Kadın & 13 hasta & 32 \\
\hline Hipertansiyon & 27 hasta & 65 \\
\hline Aktif sigara tüketimi & 9 hasta & 22 \\
\hline Koroner arter hastalığı & 9 hasta & 22 \\
\hline Operasyon zamanlaması & & \\
Acil & 4 hasta & 10 \\
Erken & 6 hasta & 14 \\
Elektif & 31 hasta & 76 \\
\hline Geçirilmiş kardiyak cerrahi & 14 hasta & 34 \\
\hline Asendan aorta çapı & & \\
Ortalama & 7,2 cm & \\
Minimum-maksimum & $4,7-15 \mathrm{~cm}$ & \\
\hline İnsizyon & & \\
Median sternotomi & 39 hasta & 95 \\
Clamshell & 2 hasta & 5 \\
\hline Arteriyel kanülasyon yeri & & \\
Femoral arter & 15 hasta & 37 \\
Sağ subklavien arter & 17 hasta & 41 \\
Asendan aorta & 8 hasta & 20 \\
Sol subklavien arter & 1 hasta & 2 \\
\hline
\end{tabular}

\section{Bulgular}

Cerrahi teknik olarak 20 hastada asendan aort, 15 hastada aort kökü, 6 hastada arkus aorta replasmanı uygulandı. Perfüzyon stratejisi olarak derin hipotermik sirkülatuar arrest (34 hasta, \%82,9) ve antegrad serebral perfüzyon (7 hasta, \%17,1) uygulandı. Tüm

Ege Tıp Dergisi 
hastalarda saptanan ortalama kardiyopulmoner by-pass süresi $210,1 \pm 67 \mathrm{dk}$, miyokard iskemi süresi ise $116,3 \pm 43 \mathrm{dk}$ olarak saptandı. Ortalama serebral iskemi süresi $27,6 \pm 9 \mathrm{dk}$ olarak bulundu.

Postoperatif komplikasyon olarak 3 hastada reeksplorasyon gerektiren kanama, 2 hastada diyaliz gerektiren böbrek yetmezliği, 5 hastada uzamış mekanik ventilatör desteği saptandı. İki hastada 10 ünite üzeri eritrosit süspansiyonu transfüze edilmiş olup, 3 hastada hiç transfüzyon yapılmamıştır. Hastaların ortalama yoğun bakım kalış süresi $4,1 \pm 5$ gün ve hastanede kalış süresi $9,8 \pm 8$ gün olarak bulundu. Nörolojik olaylara bakıldığı zaman 6 hastada (\%15) geçici nörolojik disfonksiyon gözlenirken, bir hastada multipl emboliye bağlı strok gelişti. Mortalite bir hastada (\%2) görülmüş olup bu hastada ölüm nedeni embolik strok olarak kaydedilmiştir. İntraoperatif bulgular ve postoperatif komplikasyonlar Tablo-2'de verilmiştir.

Tablo-2. Postoperatif Cerrahi Özellikler ile Komplikasyonlar.

\begin{tabular}{|c|c|c|}
\hline Özellik & Sayı & Yüzde (\%) \\
\hline $\begin{array}{l}\text { Operasyon tipi } \\
\text { Tüp greft repl. } \\
\text { Cabrol op. } \\
\text { Mod. Bentall op. } \\
\text { Arkus repl. } \\
\text { Cabrol+Arkus repl. } \\
\text { Mod. Bentall+Arkus repl. }\end{array}$ & $\begin{array}{c}20 \text { hasta } \\
6 \text { hasta } \\
9 \text { hasta } \\
3 \text { hasta } \\
2 \text { hasta } \\
1 \text { hasta }\end{array}$ & $\begin{array}{r}48 \\
15 \\
22 \\
8 \\
5 \\
2\end{array}$ \\
\hline $\begin{array}{l}\text { Serebral koruma } \\
\text { DHSA } \\
\text { Antegrad serebral perf. }\end{array}$ & $\begin{array}{r}34 \text { hasta } \\
7 \text { hasta } \\
\end{array}$ & $\begin{array}{l}83 \\
17 \\
\end{array}$ \\
\hline KPB süresi & $210 \pm 67 \mathrm{dk}$ & \\
\hline Miyokard İskemi süresi & $116,3 \pm 43 \mathrm{dk}$ & \\
\hline Serebral İskemi süresi & $27,6 \pm 9 \mathrm{dk}$ & \\
\hline $\begin{array}{l}\text { Kanamaya bağlı } \\
\text { reeksplorasyon }\end{array}$ & 3 hasta & 8 \\
\hline Uzamış MV desteği & 5 hasta & 12 \\
\hline $\begin{array}{l}\text { Ortalama ERT } \\
\text { transfüzyonu } \\
\text { Masif transfüzyon } \\
\text { Transfüyon yapılmayan }\end{array}$ & $\begin{array}{c}3,6 \pm 3 \text { ünite } \\
2 \text { hasta } \\
3 \text { hasta } \\
\end{array}$ & $\begin{array}{l}5 \\
8 \\
\end{array}$ \\
\hline $\begin{array}{l}\text { Böbrek yetmezliği } \\
\text { Diyaliz gerektiren } \\
\text { Diyaliz gerektirmeyen }\end{array}$ & $\begin{array}{l}2 \text { hasta } \\
3 \text { hasta }\end{array}$ & $\begin{array}{l}5 \\
8\end{array}$ \\
\hline $\begin{array}{l}\text { Nörolojik disfonksiyon } \\
\text { Geçici } \\
\text { Kalıcı }\end{array}$ & $\begin{array}{l}6 \text { hasta } \\
1 \text { hasta }\end{array}$ & $\begin{array}{r}15 \\
2\end{array}$ \\
\hline Mortalite & 1 hasta & 2 \\
\hline
\end{tabular}

Mod: Modifiye, Op: Operasyonu, Repl: Replasmanı, DHSA: Derin hipotermik sirkülatuar arrest, Perf: Perfüzyon, KPB: Kardiyopulmoner by-pass, MV: Mekanik ventilatör, ERT: Eritrosit süspansiyonu.

\section{Tartışma}

AAAD gelişen hastaların \%90'ı akut dönemde cerrahi tedavi almaktadırlar. Bu nedenle KAAD olguları daha nadir görülmekte, araştırmalarda olgu sayıları daha kısıtlı olarak yer almaktadır. Bunun yanında aort diseksiyonunun akut safhada stabil kalmasını, bu sayede kronikleşmesini sağlayan fizyolojik ve patolojik süreçler farklıdır. Asemptomatik halde kronikleşen diseksiyon olguların yaklaşık yarısında geçirilmiş kardiyak cerrahi öyküsü saptanmaktadır. Bu hastaların ağrı duymamasının nedeni olarak önceki operasyona bağlı kardiyak denervasyon gösterilmektedir (4). Bunun yanında yapışıklıklara bağlı olarak bu hastalarda klinik durum daha gürültüsüz seyredebilir. Bu bulgulara paralel olarak, KAAD saptanan hastalarda bikuspid aort kapak hastalığı, asendan aortaya sınırlı tutulum, daha iyi fonksiyonel kapasite, daha ileri aort kapak yetmezliği ve daha sık aort kökü tutulumu gözlenir $(1,4)$. Bununla birlikte postoperatif morbidite (strok, böbrek yetmezliği, uzamış ventilatör desteği) ve mortalite daha düşüktür (2).

Peterss ve ark. (3) çalışmasında, Tip A aort diseksiyonu olgularının akut safhadan kronik safhaya geçiş süresinde aort dokusu mikroskobik olarak incelenmiş ve intimal flepte, media tabakasında ve adventisyada bazı histolojik değişiklikler saptanmıştır. Bu değişiklikler elastin fragmantasyonunda, medial nekroziste ve fibroziste artış şeklindedir. Aort duvarındaki bu değişiklikler sayesinde, dokular cerrahi sırasında anastomoza daha dayanıklı hale gelir ve cerrahi sonrası kanama ve yırtılma gibi komplikasyonların önlenmesini sağlar. Bu durum KAAD nedeni ile opere edilen hastaların postoperatif sonuçlarının analiz edildiği çalışmalara yansımıştır $(2,6)$.

KAAD hastalarında cerrahi tedaviye karar vermede en önemli kriterler aort çapı ve aort yetmezliğinin derecesidir. Cerrahi strateji ise aortadaki hastalığın yaygınlığına bağlıdır. Olguların neredeyse tamamında açık cerrahi onarım uygulanırken, sadece asendan aortaya sınırlı, koroner arterleri ve arkus dallarını içermeyen lezyonlarda nadiren endovasküler stent implantasyonu uygulanabilir (7). Aort kökü ve arkus aortanın tutulmadığı olgularda basit tüp greft replasmanı uygulanabilir. Bizim çalışmamızda da literatür ile benzer şekilde en sık uygulanan cerrahi teknik tüp greft replasmanı (20 hasta, \%48) olarak saptandı. KAAD olgularında akut olgulara göre aort kökünde genişleme daha fazla olmakta, asimetrik genişlemeye bağlı olarak aort kapak lifletlerinde koaptasyon kusuru daha fazla görülmektedir. Bu nedenle KAAD cerrahisinde kapak koruması daha az sıklıkta uygulanabilmektedir (4). Aort kökü tutulumlarında kapak koruyucu kök replasmanı veya kapaklı kondüit greft replasmanı uygulanabilir. Çalışmaya dâhil edilen hastalarda, aort kökü dilatasyonu ve ciddi aort kapak yetmezliği bulunması durumunda modifiye Bentall operasyonu uygulanırken, koroner butonlarının serbestleştirilemediği redo operasyonlarda Cabrol tekniği uygulanmıştır.

Uygulanacak operasyon sırasında kritik nokta serebral korumayı içeren perfüzyon stratejisidir. Bu amaçla en sık uygulanan teknik derin hipotermik sirkülatuar arrest (DHSA) altında distal anastomozun açık yapılmasıdır. Bunun yanında retrograd veya antegrad serebral perfüzyon yardımı ile daha uzun sürede, güvenli 
serebral koruma ile distal anastomoz uygulanabilir. Arkus aorta replasmanı uygulanacak olgularda, serebral iskemi süresi 30 dk'yı aşacak ise, ek serebral koruma metodu gerekli olmakta, günümüzde bunun için en çok tercih edilen yol antegrad serebral perfüzyon tekniği olarak gösterilmektedir (8). Günümüzde ılımlı hipotermi altında $\left(24-26^{\circ} \mathrm{C}\right)$, devamlı antegrad serebral perfüzyon ile anastomoz yapılmasının inme riskini artırmadığı saptanmıştır (9-11). Selektif antegrad serebral perfüzyon uygulanacak hastalarda arteriyel kanülasyon yeri önem arz eder. Bu amaçla sıklıkla sağ subklavien arter, greft yardımıyla trunkus brakiosefalikus ve sağ karotid arter kullanılabilir. Ayrıca arkus aorta içinden özel balonlu kanüller vasıtasıyla serebral perfüzyon sağlanabilir. Bizim çalışmamıza dâhil edilen hastalarda en sık kullanılan metod DHSA altında distal anastomoz uygulanmasıdır. Bu hastalarda serebral iskemi süresi ortalama $27 \mathrm{dk}$ saptanmıştır. Bu sürenin strok riski açısından güvenli aralıkta olduğu söylenebilir (12). Bunun yanında total arkus replasmanı yapılan olgularda subklavien kanül yoluyla veya greft yardımıyla antegrad serebral perfüzyon uygulanmıştır. Tüm hastalarda kalıcı strok oranı \%2,5 olup, seçilen serebral koruma yöntemlerinin güvenli olduğunu gösterebilir. Bunun yanında tüm distal anastomozlar açık şekilde yapılmıştır. Bu sayede kronikleşen diseksiyon flepi, ulaşılabilen en uç kısma kadar kesilerek fenestrasyon uygulanmış, distal aortada tek lümen oluşturulmuştur.

Çalışmamızda mortalite oranı \%2 saptanmış olup KAAD nedeniyle cerrahi uygulanmış diğer hasta serileriyle karşılaştıııldığında bu oranın düşük olduğu söylenebilir (4). Mortalitenin düşük olması, olguların çoğunlukla elektif olarak operasyona alınmasına, preoperatif klinik durumlarının stabil olmasına, risk faktörlerinin kontrol altına alınmasına ve kanülasyon yerinin bilgisayarlı tomografi ile detaylı değerlendirilerek karar verilmesine bağlanabilir.

Çalışmamızın retrospektif olarak tasarlanmış olması ve olgu sayısının kısıtlı olması zayıf yönü olarak görülmektedir. Ancak, güncel literatürde KAAD hastaları içeren serilerde de hasta sayısı sınırlıdır. Bununla birlikte hastalarda ortaya çıkan postoperatif olayların sıklığının az olması istatistiksel analizleri mümkün kılmadığı için risk faktörü analizi yapılamamıştır.

\section{Sonuç}

Kronik tip A aort diseksiyonu akut forma göre daha nadir görülmektedir. Cerrahi tedavisinde düşük mortalite oranı doğru operasyon ve perfüzyon stratejisi ile sağlanabilir. İnme, halen en önemli mortalite nedeni olarak görülmektedir.

\section{Kaynaklar}

1. Hynes CF, Greenberg MD, Sarin S, Trachiotis GD. Chronic type A aortic dissection: Two cases and a review of current management strategies. Aorta (Stamford) 2016;4(1):16-21.

2. Cabasa A, Pochettino A. Surgical management and outcomes of type A dissection: The Mayo Clinic experience. Ann Cardiothorac Surg 2016; 5(4):296-309.

3. Peterss S, Mansour AM, Ross JA, et al. Changing pathology of the thoracic aorta from acute to chronic dissection: Literature review and insights. J Am Coll Cardiol 2016;68(10):1054-65.

4. Rylski B, Milewski RK, Bavaria JE, et al. Outcomes of surgery for chronic type A aortic dissection. Ann Thorac Surg 2015;99(1):88-93.

5. Hirst AE Jr, Johns VJ Jr, Kime SW Jr. Dissecting aneurysm of the aorta: A review of 505 cases. Medicine (Baltimore) 1958;37(3):217-79.

6. Yuan $\mathrm{Q}, \mathrm{Yu} \mathrm{H}$, Karmacharya U, et al. Comparison of chronic type A aortic dissection with acute type A dissection of short-term and long-term survival rate. Int J Cardiol 2014;175(2):363-5.

7. Roselli EE, Idrees J, Greenberg RK, Johnston DR, Lytle BW. Endovascular stent grafting for ascending aorta repair in highrisk patients. J Thorac Cardiovasc Surg 2015;149(1):144-51.

8. Harky A, Fok M, Bashir M, Estrera AL. Brain protection in aortic arch aneurysm: Antegrade or retrograde? Gen Thorac Cardiovasc Surg 2018;3. doi: 10.1007/s11748-017-0879-5. [Epub ahead of print]

9. Urbanski PP, Lenos A, Bougioukakis P, Neophytou I, Zacher M, Diegeler A. Mild-to-moderate hypothermia in aortic arch surgery using circulatory arrest: A change of paradigm? Eur J Cardiothoracic Surg 2012; 41(1):185-91.

10. Keeling WB, Tian DH, Leshnower BG. Safety of moderate hypothermia with antegrade cerebral perfusion in total aortic arch replacement. Ann Thorac Surg 2018;105(1):54-61.

11. Tian DH, Wan B, Bannon PG, et al. A meta-analysis of deep hypothermic circulatory arrest versus moderate hypothermic circulatory arrest with selective antegrade cerebral perfusion. Ann Cardiothorac Surg 2013;2(2):148-58.

12. Kouchoukos NT. Straight deep hypothermic circulatory arrest for aortic arch surgery: Going the way of the dinosaurs? J Thorac Cardiovasc Surg 2017;154(6):1840-1. 